\title{
Altered expression of different GalNAc-transferases is associated with disease progression and poor prognosis in women with high-grade serous ovarian cancer
}

\author{
RAZAN SHETA ${ }^{1,2}$, MAGDALENA BACHVAROVA ${ }^{2}$, MARIE PLANTE ${ }^{2,3}$, JEAN GREGOIRE $^{2,3}$, \\ MARIE-CLAUDE RENAUD ${ }^{2,3}$, ALEXANDRA SEBASTIANELLI ${ }^{2,3}$, ION POPA $^{4,5}$ and DIMCHO BACHVAROV ${ }^{1,2}$ \\ ${ }^{1}$ Department of Molecular Medicine, Laval University, Quebec, Quebec G1V 0A6; ${ }^{2} \mathrm{CHU}$ de Québec Research Center, \\ Hotel-Dieu de Québec, Quebec, QC G1R 3S3; Departments of ${ }^{3}$ Obstetrics and Gynecology and \\ ${ }^{4}$ Molecular Biology, Medical Biochemistry, and Pathology, Laval University, QC G1V 0A6; \\ ${ }^{5} \mathrm{CHU}$ de Québec Research Center, Hospital Saint-Sacrement, Quebec, QC G1S 4L8, Canada
}

Received June 27, 2017; Accepted September 25, 2017

DOI: $10.3892 /$ ijo.2017.4147

\begin{abstract}
Protein glycosylation perturbations are implicated in a variety of diseases, including cancer. Aberrant glycosylation in cancer is frequently attributed to altered expression of polypeptide GalNAc transferases (GalNAc-Ts) - enzymes initiating mucin-type O-glycosylation. A previous study from our group demonstrated that one member of this family (GALNT3) is overexpressed in epithelial ovarian cancer (EOC), and GALNT3 expression correlated with shorter progressionfree survival (PFS) in EOC patients with advanced disease. As considerable degree of redundancy between members of the GalNAc-Ts gene family has been frequently observed, we decided to investigate whether other members of this family are essential in EOC progression. In silico analysis based on publically available data was indicative for altered expression of five GalNAc-Ts (GALNT2, T4, T6, T9 and T14) in ovarian high-grade serous carcinoma (HGSC) samples compared to
\end{abstract}

Correspondence to: Dr Dimcho Bachvarov, CHU de Québec Research Center, Hotel-Dieu de Québec, 9 rue McMahon, Quebec, Quebec G1R 3S3, Canada

E-mail:dimtcho.batchvarov@crhdq.ulaval.ca

Abbreviations: EOC, epithelial ovarian cancer; GalNAc-Ts, GalNAc transferases; HGSC, high-grade serous carcinoma; HOSE, human ovarian surface epithelial; IHC, immunohistochemistry; KD, knockdown; LMP, low-malignant potential; MD, moderately differentiated; MCA, multiple correspondence analyses; PD, poorly differentiated; PTM, post-translational modifications; PFS, progression-free survival; SOC, serous ovarian carcinomas; SNO, superficial scrapings from normal ovaries; TMAs, tissue microarrays

Key words: epithelial ovarian cancer, mucin O-glycosylation, polypeptide GalNAc transferases, immunohistochemistry, tissue microarrays, Kaplan-Meier survival curve analysis non-tumoral (control) ovarian tissue. We analyzed protein expression of these GalNAc-Ts in EOC cells and tumors by western blotting, followed by immunohistochemical (IHC) evaluation of their expression in EOC tumor and control samples using tissue microarrays (TMAs). Western blot analyses were indicative for low expression of GALNT2 and strong expression of GALNT6, T9 and T14 in both EOC cells and tumors. These observations were confirmed by IHC. GALNT2 displayed significantly lower expression, while GALNT6, GALNT9 and GALNT14 showed significantly higher expression in HGSC tumors compared to control tissue. Importantly, GALNT6 and GALNT14 expression correlated with poor prognosis of serous EOC patients. Moreover, our results suggest for overlapping functions of some GalNAc-Ts, more specifically GALNT3 and GALNT6, in directing EOC progression. Our results are indicative for a possible implication of different members of the GalNAc-T gene family in modulating EOC progression, and the potential use of GALNT6 and GALNT14 as novel prognostic EOC biomarkers. These data warrant future studies on the role of members of the GalNAc-Ts gene family in ovarian tumorigenesis.

\section{Introduction}

Epithelial ovarian cancer (EOC) accounts for $4 \%$ of all cancers in women and is the leading cause of death from gynecologic malignancies (1). Despite medical and surgical improvements, long-term survival rates for EOC patients with advanced disease remain disappointing, primarily due to its asymptomatic nature and the lack of reliable methods for early diagnosis $(2,3)$. Indeed, most women are diagnosed with EOC when micro- and macro-metastases are already present and currently, the 5-year EOC survival rate is rather disappointing $(<40 \%)$ (1). Thus, the identification of novel pro-metastatic EOC molecules and associated pathways could provide additional therapeutic targets for improved management of this deadly disease.

There are many documented studies investigating different post-translational modifications (PTMs) and their 
association with cancer; among these, aberrant glycosylation has displayed rather important roles in cancer progression $(4,5)$, including EOC dissemination (6,7). Mucin-type O-glycosylation of proteins represents the most diverse PTM form, and is considered to be a conserved type of glycosylation found in many species and organ types (8). This type of PTM is rather complex and involves the transfer of different monosaccharides to each of the six O-linked glycans (9). O-glycosylation is initiated by 20 GalNAc-transferases, a family of enzymes known as the UDP N-acetylgalactosamine: polypeptide $\mathrm{N}$-acetyl galactosaminyl transferases (GalNAc-Ts) (9), which are responsible for the transfer of the monosaccharide GalNAc from UDP-GalNAc to the hydroxyl group of the serine, threonine or tyrosine residues found in the target protein substrate (10). Interestingly, the genes comprising this family of enzymes show tissue-specific expression $(11,12)$, but also have overlapping substrate specificities, suggestive for partial functional redundancy in their function (11). Several in vitro studies have shown that GalNAc-Ts are differentially expressed in cells and tissues during development (9). Aberrant GalNAc-Ts expression patterns have been frequently observed in cancer (13), which warrants further studies on the possible implications of these enzymes in tumor progression and their potential use as therapeutic targets and/or prognostic markers (14).

We have previously identified the GalNAc-T3 (GALNT3) gene as a potential EOC oncogene, highly expressed in advanced disease, as GALNT3 expression was significantly associated with poor outcome (15). We also demonstrated that in EOC cells, GALNT3 might directly alter biosynthesis and/or aberrant glycosylation of different O-glycoproteins that could play an essential role in EOC dissemination (15-17). However, to date, no other studies have comprehensively assessed the implications of other members of the GalNAc-Ts gene family in EOC dissemination. We thus decided to examine the role of some of the GalNAc-Ts that have been reported to play essential roles in the etiology of different cancer types. Five members of this gene family (GALNT2, T4, T6, T9 and T14) have previously displayed significant alterations in their expression in different cancer types (reviewed in ref. 7). In silico analysis of the GalNAc-Ts expression profiles from publicly available data were also indicative for overexpression of some of these GalNAc-Ts (including GALNT4, T6, and T14), as well as GALNT3, in ovarian HGSC samples.

The above data prompted us to investigate the expression levels of these five GalNAc-Ts (GALNT2, T4, T6, T9 and T14) in EOC cells and EOC tumor tissues, and to correlate their expression with the corresponding clinicopathological characteristics. To our knowledge this is the first report that comprehensively examines the expression profiles of several GalNAc-Ts in EOC with the perspective of identifying novel prognostic factors for this deadly disease. We show that most of the GalNAc-Ts analyzed (including GALNT2, T6, T9 and T14) displayed altered expression in EOC cells and tumors importantly, our data are indicative for a significant association of two GalNAc-Ts (GALNT6 and T14) with progressionfree survival (PFS) values of EOC patients, suggestive for oncogenic functions of these two enzymes in EOC, and their potential use as novel EOC prognostic biomarkers.
Table I. Detailed patients' clinicopathological characteristics.

\begin{tabular}{lccr}
\hline Variable & Range & N/Total & $\%$ \\
\hline Age (years) & $\geq 65$ & $54 / 162$ & 33 \\
& $<65$ & $108 / 162$ & 67 \\
Median age & 60 & & \\
Tissue/tumor type & Normal & $18 / 162$ & 11 \\
& LMP & $13 / 162$ & 8 \\
& High-grade & $131 / 162$ & 81 \\
Grade & 3 & $126 / 131$ & 96 \\
& 2 & $5 / 131$ & 4 \\
Stage & II & $5 / 131$ & 4 \\
& III & $92 / 131$ & 70 \\
& IV & $34 / 131$ & 26 \\
Chemotherapy & Platinum+Taxol & $120 / 131$ & 92 \\
& Other & $11 / 131$ & 8 \\
CA125 $^{\text {b }}$ (U/ml) & $\geq 800$ & $59 / 118$ & 50 \\
& $<800$ & $59 / 118$ & 50 \\
PFS $^{c}$ (months) & $0-6$ & $53 / 124$ & 43 \\
& $7-24$ & $44 / 124$ & 35 \\
& $>25$ & $27 / 124$ & 22
\end{tabular}

${ }^{\mathrm{a} A l l}$ patients were subjected to adjuvant therapy. ${ }^{\mathrm{b}}$ Extended follow-up, including CA125 values, were available for 118 patients. CA125 values correspond to the baseline serum concentrations of EOC patients. ${ }^{\mathrm{c}}$ Extended follow-up, including progression-free survival (PFS) values, were available for 124 patients. PFS is defined as the time from surgery to the first observation of disease progression, recurrence or death. The follow-up was available until death or to the date the study was closed. LMP, low-malignant potential.

\section{Materials and methods}

Patient cohort. Patients included in this study were operated between January 1998 to December 2015 for advanced ovarian cancer at the CHUQ Hôtel-Dieu Hospital in Quebec City, Canada. Inclusion criteria were: serous papillary carcinoma histology, FIGO stages II, III or IV and chemotherapy received after the surgery (see Table I for detailed clinicopathological characteristics). All tumors were histologically classified according to the criteria defined by the World Health Organization (18). Disease progression was evaluated following the guidelines of the Gynecology Cancer Intergroup (18). PFS was defined as the time from surgery to the first observation of disease progression, recurrence or death. The follow-up was available until death or to the date the study was closed (30 December 2016). Nineteen non-tumoral (control) ovarian samples were derived from women subjected to hysterectomy with oophorectomy due to non-ovarian pathologies.

Ethics statement approval and consent to participate. The study was approved by the Clinical Research Ethics Committee of the Hotel-Dieu de Québec Hospital, and all patients signed 
Table II. Dilution and technique used for each antibody in IHC and western blot analyses.

\begin{tabular}{|c|c|c|c|c|c|c|c|}
\hline Antibody & Species & Dilution TMA & Company & Retrieval & Incubation TMA & Dilution WB & Incubation WB \\
\hline Anti-GALNT2 & Rabbit & $1: 50$ & Abcam & Microwave & $4^{\circ} \mathrm{C}$ overnight & $1: 1,000$ & $4^{\circ} \mathrm{C}$ overnight \\
\hline Anti-GALNT4 & Rabbit & $1: 100,1: 50,1: 25$ & Proteintech & $\begin{array}{l}\text { Microwave/ } \\
\text { pronase }\end{array}$ & $4^{\circ} \mathrm{C}$ overnight & $1: 500$ & $4^{\circ} \mathrm{C}$ overnight \\
\hline Anti-GALNT6 & Mouse & $1: 75$ & Abcam & Microwave & $4^{\circ} \mathrm{C}$ overnight & $1: 1,000$ & $4^{\circ} \mathrm{C}$ overnight \\
\hline Anti-GALNT9 & Rabbit & $1: 100$ & $\begin{array}{l}\text { LifeSpan } \\
\text { BioScience }\end{array}$ & Microwave & $4^{\circ} \mathrm{C}$ overnight & $1: 1,000$ & $4^{\circ} \mathrm{C}$ overnight \\
\hline Anti-GALNT14 & Rabbit & $1: 100$ & Abcam & Microwave & $4^{\circ} \mathrm{C}$ overnight & $1: 1,000$ & $4^{\circ} \mathrm{C}$ overnight \\
\hline Anti- $\beta$-actin & Mouse & N/A & Santa Cruz & N/A & N/A & $1: 2,000$ & $\begin{array}{l}1 \mathrm{~h} / \text { room } \\
\text { temperature }\end{array}$ \\
\hline
\end{tabular}

IHC, immunohistochemistry; TMA, tissue microarray; WB, western blotting.

an informed consent for voluntary participation and agreed to report individual patient data.

Cell culture. The EOC cell lines SKOV3 and CaOV3 were purchased from the American Tissue Type Collection; OV-90, OV2008, TOV-112 and TOV-21 cell lines were a kind gift from Dr Anne-Marie Mes-Masson (Montreal University), A2780s and A2780cp cell lines were a kind gift from Dr Benjamin Tsang (Ottawa University), the OVCAR4 cell line was a kind gift from Dr Stephan Gobeil (Laval University), and the two human ovarian surface epithelial (HOSE) cell lines; HOSE 6.3 and 17.1 were a kind gift from Dr Francis Jacob (University Hospital Basel). The cell lines were passaged in different culture media supplemented with $10 \%$ fetal bovine serum, and $1 \%$ penicillin streptomycin or $50 \mu \mathrm{g} / \mathrm{ml}$ of gentamicin as described previously (15).

Western blotting. Western blot analysis was performed as previously described (15). Briefly, protein lysates of the EOC and HOSE cell lines, were prepared by suspending cell pellets in Laemmli sample buffer containing 5\% $\beta$-mercaptoethanol. Ovarian tumor tissue and non-tumoral tissues were homogenized and sonicated in RIPA buffer [50 mM Tris (pH 7.4), $150 \mathrm{mM} \mathrm{NaCl}, 0.5 \%$ sodium deoxycholate, $0.1 \%$ SDS, $1 \%$ Triton X-100] containing protease and phosphatase inhibitors, samples were then incubated on ice for $15 \mathrm{~min}$. Protein samples from cells and tissues were measured using a BCA protein assay kit (Thermo Scientific Pierce, Rockford, IL, USA). BSA standard or samples $(20 \mu \mathrm{l})$ were transferred to a 96 well plate to which $200 \mu \mathrm{l}$ working reagent was added (working reagent $50: 1$ ratio of assay reagents $\mathrm{A}$ and $\mathrm{B}$ ). The plate was incubated for $30 \mathrm{~min}$ at $37^{\circ} \mathrm{C}$, the plates were then analyzed with a spectrophotometer at $560 \mathrm{~nm}$ [iMARK microplate reader (Bio-Rad Hercules, CA, USA)]. After centrifugation at 13,300 rpm for $15 \mathrm{~min}$ at $4^{\circ} \mathrm{C}$, the supernatant was taken and $20-30 \mu \mathrm{g}$ of the protein were used for sample preparation. Protein lysates were separated by $6-12 \%$ Tris-glycine gel electrophoresis and transferred onto a polyvinylidene difluoride membrane using a semidry apparatus (Bio-Rad Laboratories, Mississauga, ON, Canada). The membrane was blocked with $4 \%$ non-fat dry milk in TBST $(20 \mathrm{mmol} / 1$ Tris- $\mathrm{HCl}, 0.5 \mathrm{M} \mathrm{NaCl}$ and $0.1 \%$ Tween-20), and the membranes were incubated overnight with the primary antibody at $4^{\circ} \mathrm{C}$ or $1 \mathrm{~h}$ at RT (for a list of all the antibodies used in this study refer to Table II). After $3 \times 15$ min washes with TBST $(20 \mathrm{mmol} / \mathrm{l}$ Tris- $\mathrm{HCl}, 0.5 \mathrm{M} \mathrm{NaCl}$ and $0.1 \%$ Tween-20) at room temperature, the membranes were incubated with horseradish peroxidase-conjugated secondary antibody and detected with ECL solution (Thermo Fisher Scientific, Waltham, MA, USA).

Tissue micro arrays (TMAs) and immunohistochemistry (IHC). TMAs were constructed as previously described (15). Briefly, one representative block of each ovarian tumor and control ovarian tissue was selected for the preparation of the tissue arrays. Three 0.6-mm cores of tumor were taken from each tumor block and placed, $0.4 \mathrm{~mm}$ apart, on a recipient paraffin block using a commercial tissue arrayer (MTA-II arrayer) (Beecher Instruments, Silver Spring, MD, USA). The cores were randomly placed on one of three recipient blocks to avoid evaluation biases.

IHC analyses were performed, as previously described (15). Briefly, 4- $\mu \mathrm{m}$ tissue sections were deparaffinised and rehydrated in graded alcohols, then incubated with blocking serum for $20 \mathrm{~min}$. Following treatment with $3 \% \mathrm{H}_{2} \mathrm{O}_{2}$ for $10 \mathrm{~min}$ to quench the endogenous peroxidise activity, sections were incubated with the primary antibody overnight at $4^{\circ} \mathrm{C}$ (for a list of all the antibodies used in this study refer to Table II). Incubation and detection with SignalStain 3,3'-diaminobenzidine (DAB) Substrate kit (IDetect Universal Mouse Kit HRP-DAB; ID Labs, Buffalo, NY, USA) were done according to the manufacturer's instructions. Sections were then counterstained with hematoxylin. Images were acquired using a Leica Confocal Scope (TCS SP5 X; Leica Microsystems, Exton, PA, USA) and analyzed via the Leica Application Suite Software (Leica Microsystems).

Scoring and statistical analysis. Protein expression was scored according to intensity (value of 0 for absence, 1 for low, 2 for moderate, and 3 for high) of staining based on manual visualization. A composite score was defined as the product 
A

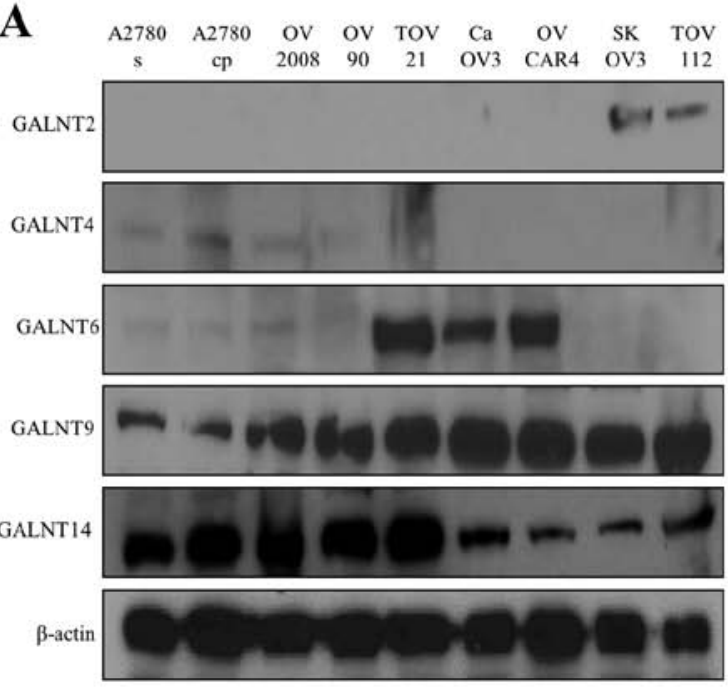

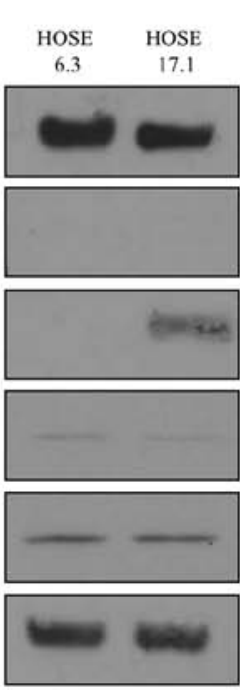

B

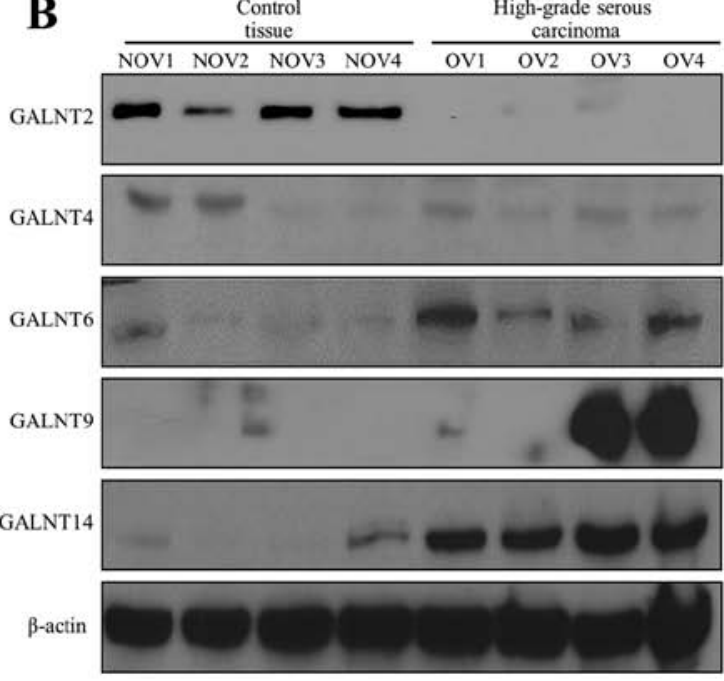

Figure 1. GalNAc-Ts expression in EOC cells and EOC tumors. (A) Western blot analysis of endogenous GALNT2, T4, T6, T9 and T14 protein expression in different EOC cell lines and the HOSE cell lines. (B) Western blot analysis of endogenous GALNT2, T4, T6, T9 and T14 protein expression in 4 HG ovarian samples (OG1-OG4) and 4 non-tumoral ovarian tissue (control tissue) samples (NOV1-NOV4). $\beta$-actin was used as a loading control. EOC, epithelial ovarian cancer; HOSE, human ovarian surface epithelial; NOV, normal ovarian; OV, ovarian tumor.

of staining intensity (nuclear, cytoplasmic, or membranous depending on the expected staining). All slides were independently scored in a blinded manner by 2 observers, and the integration was $>85 \%$. In case of differences between the 2 scorings, the core was re-evaluated to reach a consensus. The relationship between the protein expression of the listed genes in HGSC and LMP tumors, and control ovarian tissues was evaluated by the Wilcoxon two-sample test. A significant association was considered when p-values were $<0.05$.

Multiple correspondence analysis (MCA) was used to produce 2-dimensional displays of similarities of the relative expression patterns amongst the five GalNAc-Ts staining intensity in the different patient samples. MCA statistical analyses were carried out using SPSS software, version 13.0. Survival analysis results were visualized using Kaplan-Meier survival curve analysis (SPSS software, version 13.0). A Kaplan-Meier curve and the log-rank test were performed based on PFS values to test the effect of the intensity of the gene $(3,2$ vs. 0,1$)$ on disease progression. The relationship between the GalNAc-Ts staining intensity and PFS was determined by the non-parametric Mantel-Cox log-rank test to compare survival distributions (SPSS software, version 13.0). Bivariate and multivariate analyses, taking into account standard or strongly associated prognostic variables, were performed to identify independent prognostic factors and a statistic test p-value of $<0.05$ was considered statistically significant.

\section{Results}

Analyses of the expression profiles of different members of the GalNAc-Ts family in both ovarian HGSC tumors and EOC cell lines. Initially, we investigated GalNAc-Ts expression profiles from publicly available data generated from samples found in the independently derived Affymetrix GeneChip Human Genome U133 Plus 2.0 [HG-U133_Plus_2] (19). The in silico data examined were based on global gene expression analysis of differentially expressed candidate mRNAs in 21 moderately differentiated (MD) and poorly differentiated (PD) serous ovarian carcinomas (SOC) (MD/PD SC), 13 serous ovarian borderline (SOBT), and seven superficial scrapings from normal ovary (SNO) samples (19). These analyses showed significant correlation and high fold change in the overexpression of several GalNAc-Ts in the SOC samples compared to both the SBOT and SNO samples including: GALNT3, GALNT4, GALNT6, and GALNT14. Based on the above in silico analyses, as well as on literature data (as can be seen in Introduction), we decided to further proceed with investigating the expression levels of five GalNAc-Ts (GALNT2, T4, T6, T9 and T14) in EOC specimens by western blotting. The protein expression levels of these GalNAc-Ts were initially analyzed in nine EOC cell lines and in two HOSE cell lines (Fig. 1A). As seen from Fig. 1A, GALNT2 displayed lack of expression in seven EOC cell lines studied and quite a weak expression in SKOV3 and TOV112 EOC cells, compared to its rather strong expression in the two control HOSE cell lines, indicative for a suppression of this enzyme in EOC cells. GALNT4 showed very weak, or lack of expression in all (both EOC and HOSE) cell lines analyzed. GALNT6 expression was highly observed in three EOC cell lines (TOV21, CaOV3 and OVCAR4) while showing no, or weak expression in the two HOSE cell lines (Fig.1A). Finally, both GALNT9 and GALNT14 displayed very high expression in all EOC cell lines and almost lack of expression in the HOSE cell lines (Fig. 1A).

Further analyses of the protein expression levels of the selected GalNAc-Ts in four ovarian HGSC tumor samples and four control ovarian tissue samples were quite confirmatory to the data obtained with the EOC and HOSE (control) cell lines (Fig. 1B). Indeed, GALNT2 showed a relatively high expression in all control samples, while no expression was observed in the HGSCs, while GALNT4 showed an analogous pattern of rather weak or no expression between control tissues and HGSC tumors. Correspondingly, GALNT6 showed a relatively high expression in the HGSCs tumor samples compared 
A a

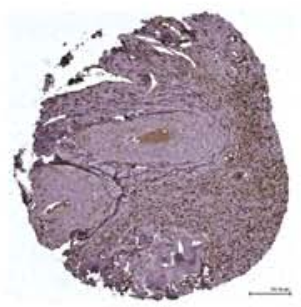

B a

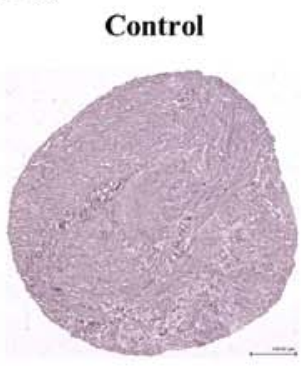

C a
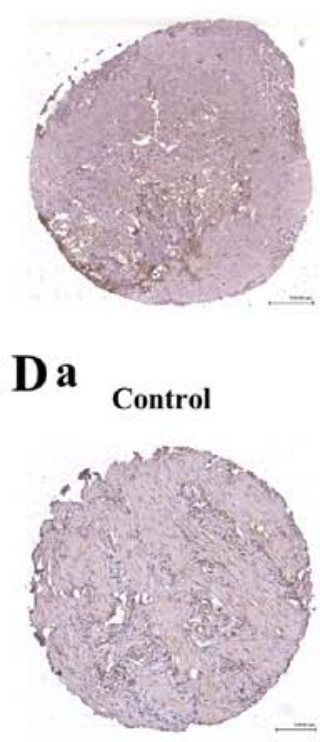

E a

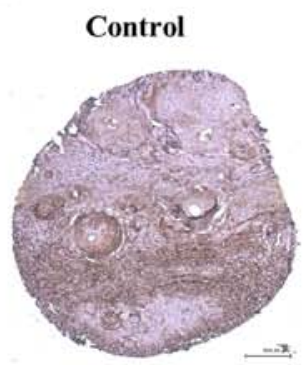

LMP

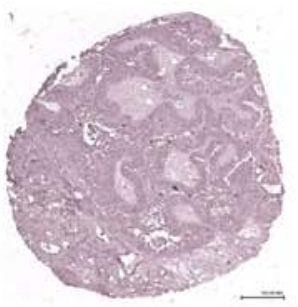

LMP

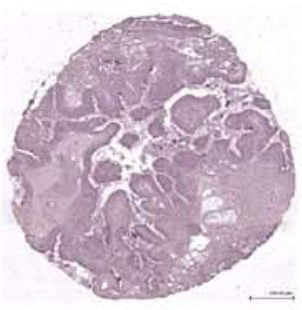

LMP

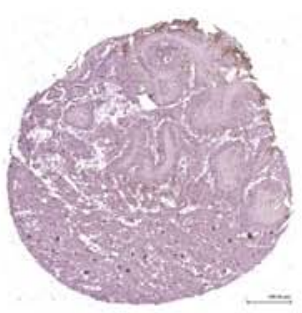

LMP

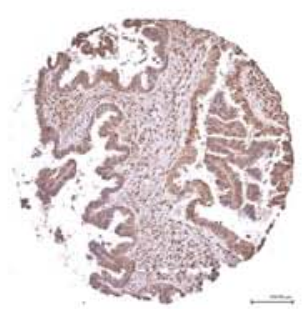

LMP

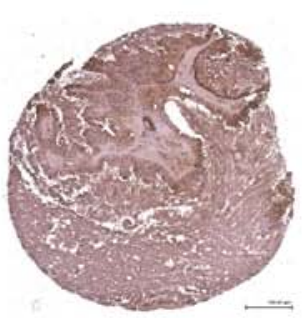

HG

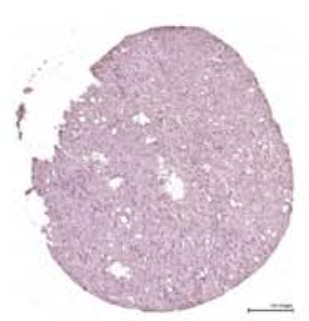

HG

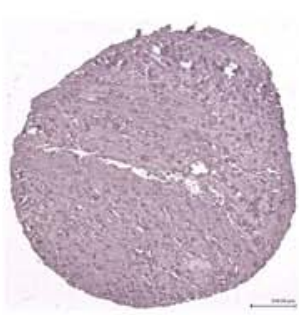

b

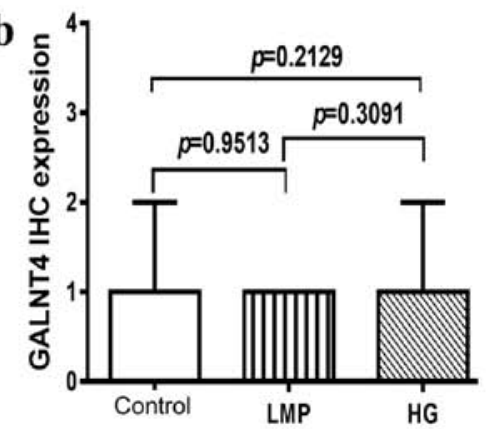

b

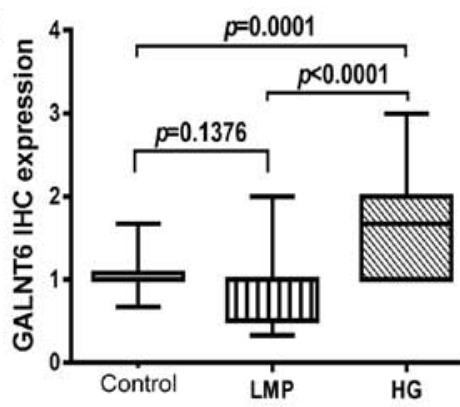

b
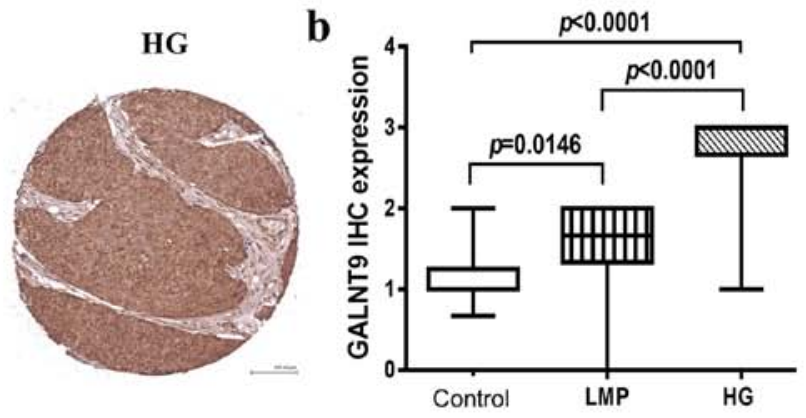

b

HG
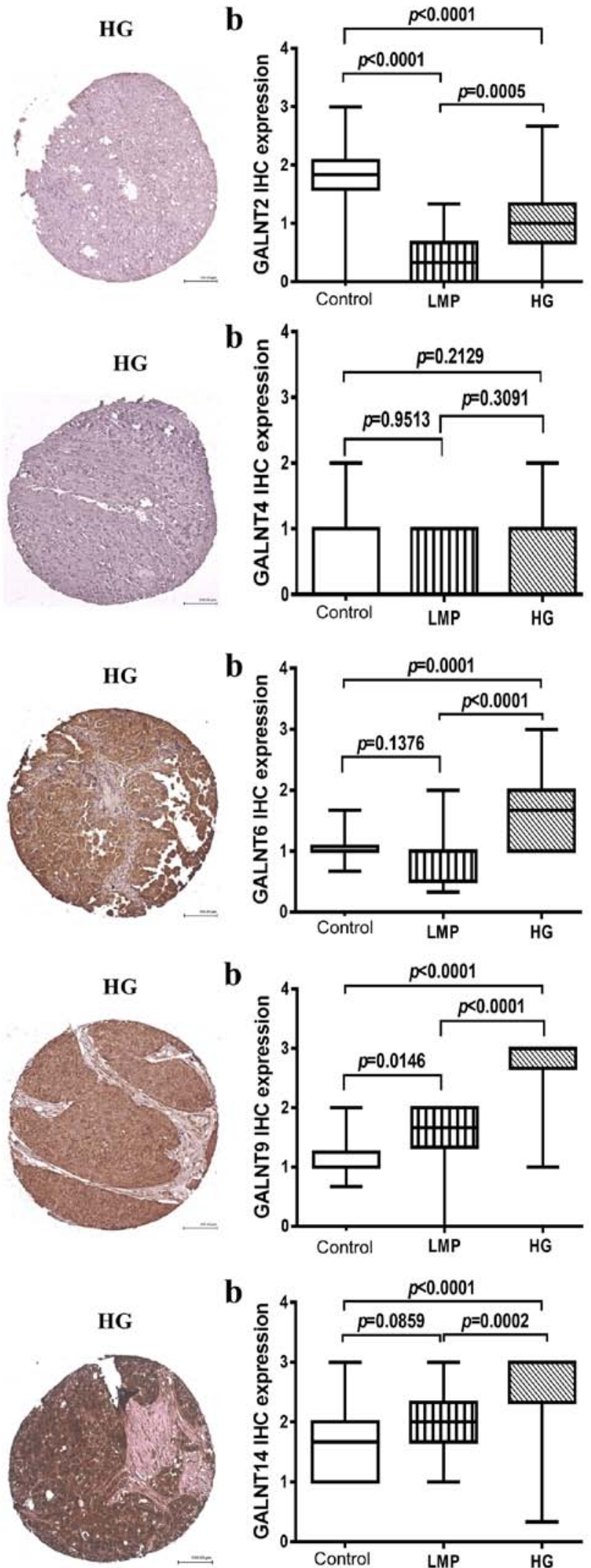

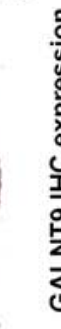

$p<0.0001$

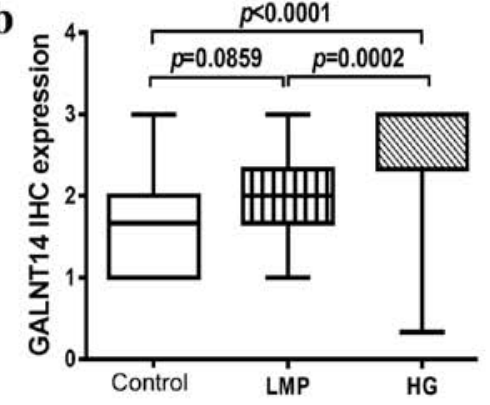

Figure 2. GalNAc-Ts protein expression in HG samples compared to LMP and non-tumoral ovarian samples. (A) a, GALNT2 staining patterns in representative cores in control ovarian tissues, LMP tumors and HG tumors. b, Box-plot presentation of GALNT2 protein expression levels in control ovarian tissues, LMP tumors and HG tumors. (B) a, GALNT4 staining patterns in representative cores in control ovarian tissues, LMP tumors and HG tumors. b, Box-plot presentation of GALNT4 protein expression levels in control ovarian tissues, LMP tumors and HG tumors. (C) a, GALNT6 staining patterns in representative cores in control ovarian tissues, LMP tumors and HG tumors. b, Box-plot presentation of GALNT6 protein expression levels in control ovarian tissues, LMP tumors and HG tumors. (D) a, GALNT9 staining patterns in representative cores in control ovarian tissues, LMP tumors and HG tumors. b, Box-plot presentation of GALNT9 protein expression levels in control ovarian tissues, LMP tumors and HG tumors. (E) a, GALNT14 staining patterns in representative cores in control ovarian tissues, LMP tumors and HG tumors. b, Box-plot presentation of GALNT14 protein expression levels in control ovarian tissues, LMP tumors and HG tumors. All p-values were derived from log-rank tests. Error bars denote standard deviation of each mean calculation. HG, high-grade; LMP, low-malignant potential. 
A

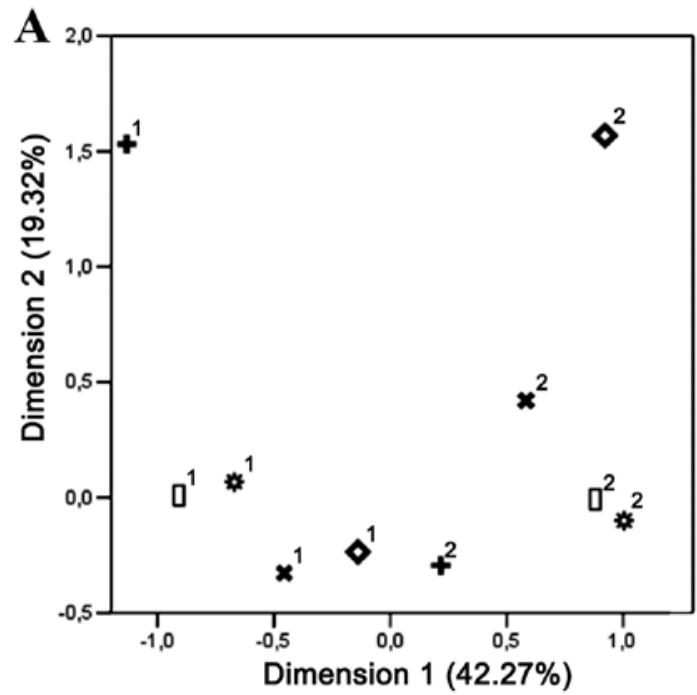

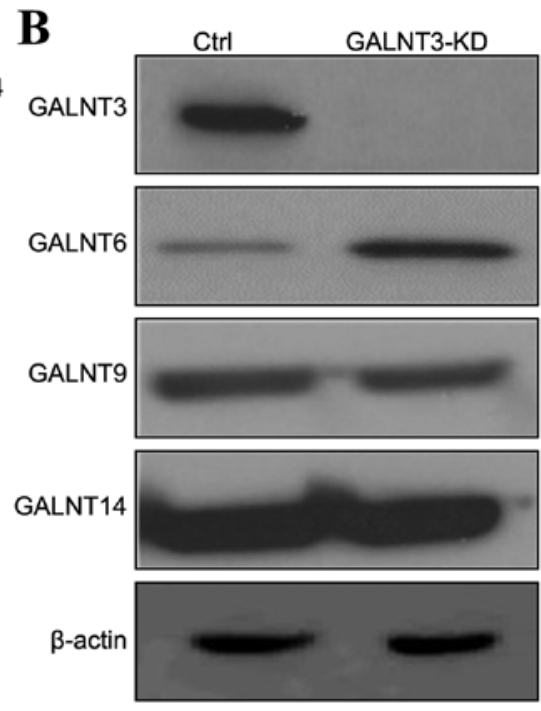

Figure 3. (A) Multiple correspondence analyses (MCA) of the relationship of the GalNAc-Ts expression in the HG ovarian tissue samples. Two major groups, separated by the first and second components, are observed. The first group includes the genes GALNT6 and T9 showing a somewhat overlapping expression pattern in the cohort of patients examined in the study. The second group indicates the inverse correlation observed between GALNT2 and GALNT14. For each analysis, the percentage of variance explained by the first two dimensions is indicated in parenthesis. (B) Western blot analysis of GALNT3, T6, T9 and T14 expression in control (Ctrl) and GALNT3 knockdown (KD) A2780s clones. $\beta$-actin was used as a loading control. HG, high-grade.

to control tissues, and again, GALNT9 and GALNT14 displayed the strongest overexpression levels in HGSCs, relative to the controls (Fig. 1B).

IHC analysis of the expression patterns of five GalNAc-Ts in numerous EOC tumors using TMAs. We next proceeded with evaluating the GalNAc-Ts expression levels by IHC in TMAs comprising triplicate cores of 131 HGSCs and 13 LMP tumors, and including 18 control ovarian tissue specimens. Table I shows the major clinical characteristics of these patients for whom extensive follow-up clinical data were available. The age ranged from 38 to 91 years (median: 60 years). HGSC tumors were grade 3 [126 patients (96\%) and grade 2 (5 patients (4\%)]. Grade 3 tumors included stage III (70\%) and stage IV (26\%) tumors, while grade 2 tumors included stage II (4\%). Most patients (92\%) received standard treatment of cytoreductive surgery followed by platinum/ taxane chemotherapy regimens. The median baseline CA125 was $\sim 800$. Forty-three percent of the patients had a progression or a recurrence within the first 6 months of follow-up; for $35 \%$ of the patients the PFS interval was in the range of 7 to 24 months, and $22 \%$ of the patients displayed PFS values $>25$ months. The mean score for expression was defined by the extent and intensity of immunohistochemistry staining for GALNT2, T4, T6, T9 and T14 (Fig. 2). As expected, GALNT2 displayed highly significant expression (strong cytoplasmic granular staining) in control tissues compared to negative staining in both LMP $(\mathrm{p}<0.0001)$ and HGSC tumors ( $\mathrm{p}<0.0001)$ (Fig. 2A). As previously, GALNT4 showed negative expression in all cases (tumor samples and control tissues), despite repeated attempts with various retrieval systems, antibody concentration, incubating time, or signal enhancements systems (Fig. 2B). GALNT6 showed a strong diffuse cytoplasmic staining which was exclusively present in HGSCs compared to control tissues $(\mathrm{p}=0.0001)$ and LMP tumors $(\mathrm{p}<0.0001)$ (Fig. 2C). A similar expression pattern was also observed for GALNT9 and GALNT14, as both these GalNAc-Ts were significantly overexpressed in HGSC tumors, when compared to control tissues $(\mathrm{p}<0.0001)$, and $(\mathrm{p}<0.0001)$ respectively (Fig. 2D and E); however, GALNT9 also displayed significant overexpression in LMP tumors compared to control samples $(\mathrm{p}=0.0146)$ (Fig. 2D), while no significant difference in GALNT14 protein expression was observed between LMP tumors and control tissues $(\mathrm{p}=0.0859)$ (Fig. 2E).

The above results, as well as data from our previous study (15) are indicative for the simultaneous overexpression of several GalNAc-Ts in EOC cell lines and tumor tissues (including GALNT3, T6, T9 and T14). Since a considerable degree of redundancy between the different members of the GalNAc-Ts gene family has been frequently observed (20), we decided to apply the MCA approach in order to more deeply investigate the extent of overlapping expression of these GalNAc-Ts among the EOC tumor samples included in this study. Two quantitative variables are included in the analysis based on staining intensity: i) for positive staining in patient samples, and ii) for negative staining in patient samples. The two dimensions of the MCA explained $42.27 \%$ (dimension 1) and $19.32 \%$ (dimension 2) of the total data variability, respectively (Fig. 3A). These analyses were indicative for a strong and a highly overlapping relationship between GALNT3 and GALNT6, as additionally, some overlapping relationship between GALNT6 and GALNT9 cannot be excluded (Fig. 3A). GALNT14 showed the highest diversity between staining 1 and 2, with no observed overlap with the other 4 genes (Fig. 3A). GALNT2 confirmed our previous data showing a complete inverse relationship to the other 4 genes, as GALNT2 staining expression 1 and 2 showed a high inverse correlation to expression pattern observed for GALNT14, and overall differential expression to those of GALNT3, T6 and T9 (Fig. 3A). The MCA-suggested GALNT3/T6 redundancy was further confirmed by examining protein 
A

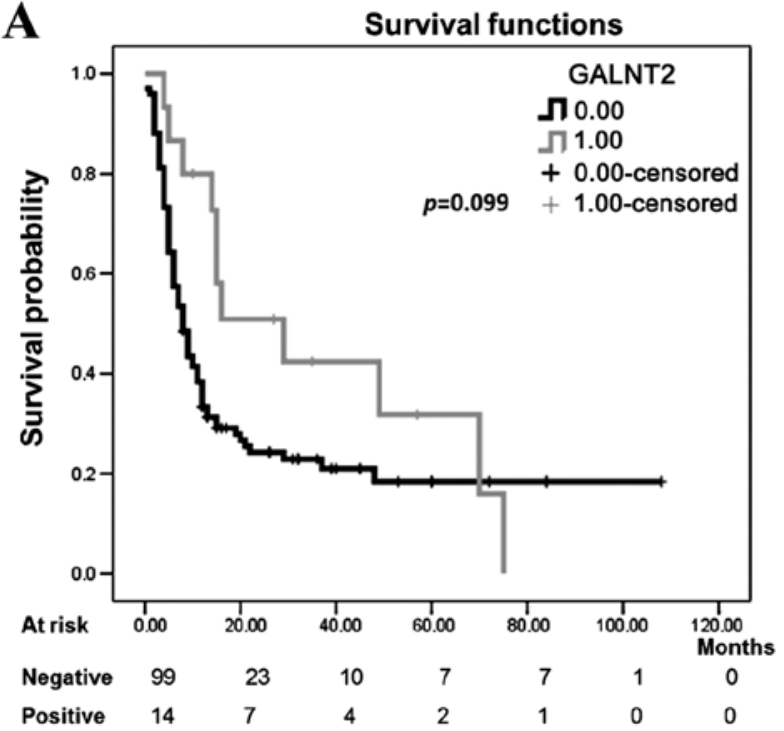

C

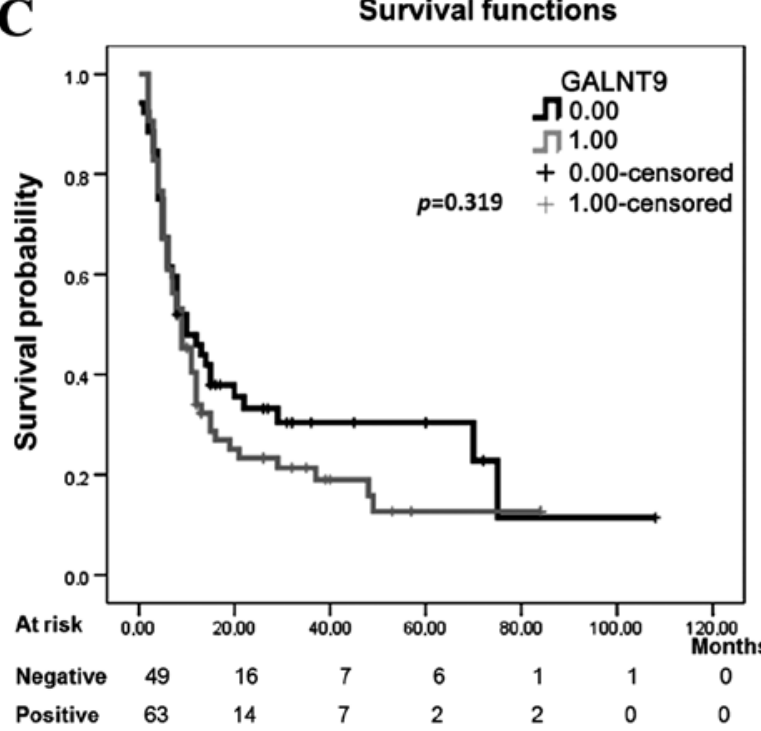

B

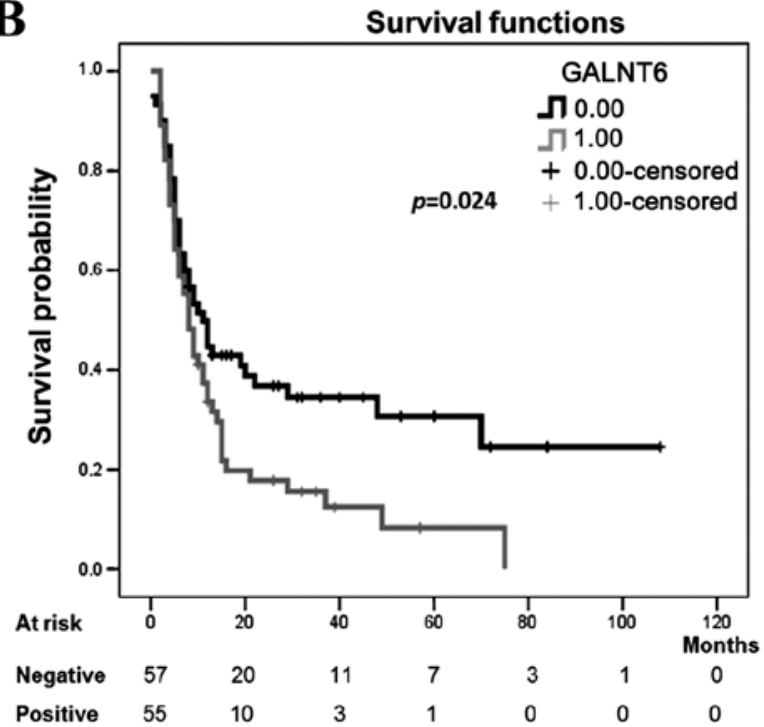

D

Survival functions

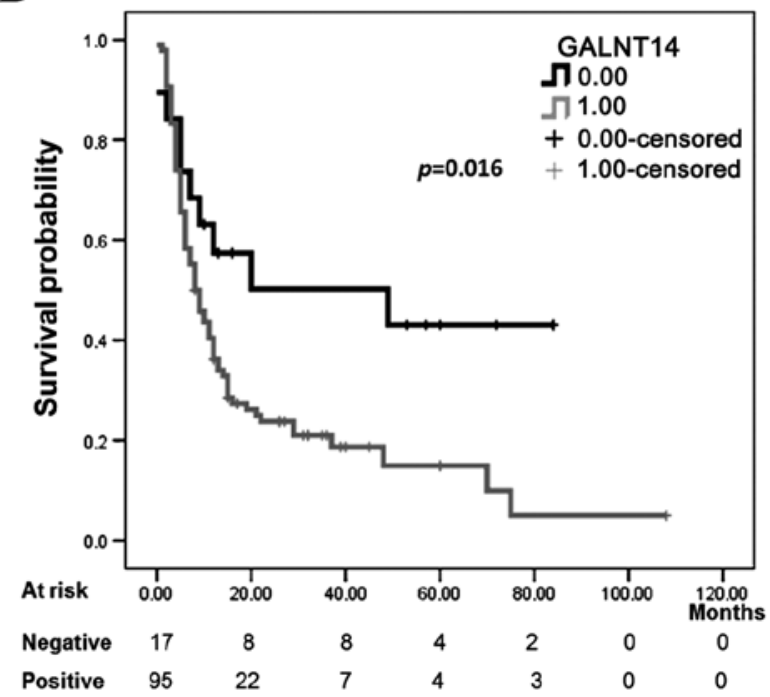

Figure 4. Kaplan-Meier progression-free survival curves showing the association between GalNAc-Ts expression patterns and prognosis in HG ovarian cancer. Kaplan-Meier survival curve analysis of HG cases for progression-free survival (PFS), presented as survival probability, of patients whose tumors show a defined staining pattern. For evaluation of GalNAc-Ts staining, HG ovarian cancer subjects were divided into two groups, those with positive staining (3 or 2 gene staining intensity) defined here as 1,00 on the Kaplan-Meier curves and those with negative staining ( 1 or 0 gene staining intensity) defined here as 0.00 on the Kaplan-Meier curves. The staining pattern for (A) GALNT2 protein, negative ( $n=101)$, and positive ( $\mathrm{n}=15)$. (B) GALNT6 protein, negative ( $\mathrm{n}=60)$, and positive $(n=56)$. (C) GALNT9 protein, negative $(n=52)$, and positive $(n=64)$. (D) GALNT14 protein, negative $(n=19)$, and positive $(n=97)$. All p-values were derived from log-rank tests. HG, high-grade.

expression profiles of GALNT6, T9 and T14 in the GALNT3 knockdown (KD) clone, previously generated in the EOC cell line A2780s (15). As shown in Fig. 3B, we observed a clear upregulation in GALNT6 protein expression in the GALNT3 KD clone, while no expression alterations were observed for both GALNT6 and T14.

Association of GalNAc-Ts expression with clinicopathological data. We further proceeded to investigate the prognostic values of the four differentially expressed GalNAc-Ts (T2, T6, T9 and T14) in EOC patients, as we evaluated the relationship between the TMA immunostaining of the 4 GalNAc-Ts and the patient PFS data using Kaplan-Meier survival curve analyses. PFS follow-up data were available for 124 patients (Table I). The analyses were based on the staining intensities: low (includes staining levels of <2) and high (includes staining levels of $>2$ ) (Fig. 4). No significant differences were observed between GALNT2 and T9 expression levels and the patient PFS values $(\log -\mathrm{rank}=2.715, \mathrm{p}=0.099)$ and (log-rank=0.995, $\mathrm{p}=0.319$ ) respectively (Fig. 4A and $\mathrm{C}$ ), which suggests that staining intensities for both GALNT2 and T9 in pre-treatment surgical EOC specimens are not predictive of PFS. However, there was a significant association between PFS and the expression of the two GalNAc-Ts T6 and T14 (log-rank=5.119, p=0.024) and (log-rank=5.770, p=0.016) respectively (Fig. 4B and D).

Bivariate and multivariate analyses to predict PFS were also performed on all the 4 genes. Multivariate analyses taking into account standard or strongly associated prognostic variables (age, grade, stage and initial CA125) were performed 
Table III. Cox regression analysis to predict progression-free survival (PFS).

\begin{tabular}{|c|c|c|c|c|c|c|c|c|c|}
\hline \multirow[b]{2}{*}{ Marker } & \multirow[b]{2}{*}{ Value } & \multirow[b]{2}{*}{$\begin{array}{c}\text { Frequency } \\
\mathrm{N}(\%)\end{array}$} & \multirow[b]{2}{*}{$\begin{array}{l}\text { Event } \\
\mathrm{n}(\%)\end{array}$} & \multicolumn{3}{|c|}{ Crude } & \multicolumn{3}{|c|}{ Adjusted } \\
\hline & & & & HR & $95 \% \mathrm{CI}$ & P-value & $\mathrm{HR}^{\mathrm{a}}$ & $95 \% \mathrm{CI}^{\mathrm{b}}$ & P-value \\
\hline \multirow[t]{2}{*}{ GALNT2 } & Negative & $101(87.1 \%)$ & $78(77.2 \%)$ & 1.0 & & & 1.0 & & \\
\hline & Positive & $15(12.9 \%)$ & $11(73.3 \%)$ & 0.599 & $0.317-1.130$ & 0.113 & 0.339 & $0.103-1.119$ & 0.076 \\
\hline \multirow[t]{2}{*}{ GALNT6 } & Negative & $60(51.7 \%)$ & $40(66.7 \%)$ & 1.0 & & & 1.0 & & \\
\hline & Positive & $56(48.3 \%)$ & $49(87.5 \%)$ & 1.596 & $1.047-2.434$ & 0.030 & 1.672 & $1.043-2.682$ & 0.033 \\
\hline \multirow[t]{2}{*}{ GALNT9 } & Negative & $52(44.8 \%)$ & $37(71.2 \%)$ & 1.0 & & & 1.0 & & \\
\hline & Positive & $64(55.2 \%)$ & $52(81.3 \%)$ & 1.232 & $0.807-1.880$ & 0.334 & 1.470 & $0.939-2.300$ & 0.092 \\
\hline \multirow[t]{2}{*}{ GALNT14 } & Negative & $20(17.2 \%)$ & $11(55.0 \%)$ & 1.0 & & & 1.0 & & \\
\hline & Positive & $96(82.8 \%)$ & $78(81.3 \%)$ & 2.185 & $1.117-4.275$ & 0.022 & 2.163 & $1.032-4.534$ & 0.041 \\
\hline
\end{tabular}

${ }^{a}$ Adjusted for age, stage, grade, and baseline CA125. The hazards models were applied to adjust for the baseline patients' characteristics. ${ }^{\text {'The }}$ confidence interval was based on the arithmetic mean of the gene expression values of the selected cases from this study. HR, hazard ratio; CI, confidence interval. Bold, statistically significant.

to identify independent prognostic factors. Multivariate analyses showed a significant association for both GALNT6 and GALNT14 and the higher risk of progression (HR, 1.672; CI, 1.043-2.682; $\mathrm{p}=0.033)$ and (HR, 2.163; CI, 1.032-4.534; $\mathrm{p}=0.041$ ) respectively (Table III), but not for GALNT2 and GALNT9 (HR, 0.339; CI, 0.103-1.119; p=0.076) and (HR, 1.470; CI, 0.939-2.300; $\mathrm{p}=0.092$ ) respectively (Table III). Taken together, our findings indicate that GALNT6 and T14 may represent useful markers to predict PFS of women with high grade serous EOC.

\section{Discussion}

Accumulating data are indicative for the important role of glycosylation perturbations in carcinogenesis, including also the abnormal expression of glycans, exclusively involved in embryonic development under normal conditions (21). Glycan alterations can be associated with cancer cell signaling and communication, tumor cell dissociation, migration and invasion, cell-matrix interactions, tumor angiogenesis, immune modulation and metastasis formation $(22,23)$, and can serve as important biomarkers and/or therapeutic targets (24).

Altered expression of glycans in cancer is frequently attributed to aberrant expression of different members of the GalNAc-Ts family in malignant tumors compared to non-tumoral tissue $(7,14)$. The deregulation in the expression of the different GalNAc-Ts allows them to play diverse roles in carcinogenesis (14). We have previously reported that one member of these GalNAc-Ts (GALNT3) represents a potential EOC oncogene, as its expression significantly correlated with shorter PFS intervals in EOC patients with advanced disease (15); however, data concerning the implication of other members of the GalNAc-Ts gene family in EOC dissemination are rather scarce. Indeed, only one study was suggestive for a possible role of GALNT14 in mediating the malignant behavior of EOC cells (25). Otherwise, some of the most extensively studied GalNAc-Ts in cancer include GALNT2, T4, T6, T9 and T14 (7), which represent the transferases included in the present study. Thus, concerning GALNT2, only one study is suggestive for a possible oncogenic role of this transferase in oral cancer (26), while other studies in different cancer types, including neuroblastoma, liver and gastric cancer, are strongly supportive for a role of GALNT2 in suppressing tumorigenesis (27-29). GALNT4 has also displayed discrepant roles in different cancers, as an implication of GALNT4 in breast carcinogenesis has been repeatedly demonstrated (30-32); however low GALNT4 expression was associated with poor PFS and overall survival of clear cell renal cell carcinoma patients (33). GALNT6 has been extensively studied for its implication in the malignant transformation and metastasis of epithelial cancers (34-37), and especially in breast cancer (38-40), where GALNT6 has been suggested as a novel marker for breast cancer detection and potential therapeutic target (41-44). Similarly to GALNT2 and T4, literature data for the role of GALNT9 in carcinogenesis is rather contradictory, since a protective role of GALNT9 was suggested in neuroblastoma and breast cancer dissemination $(45,46)$, while a recent report was indicative for an oncogenic function of this enzyme in colorectal cancer (47). Interestingly, GALNT9 was among the genes identified as potentially hypomethylated and overexpressed in advanced EOC as reported in our previous study (48). Finally, GALNT14 has been characterized as an oncogene in breast and lung cancer (49-51); moreover, recent data are strongly indicative for a role of this transferase in mediating chemotherapy resistance in different cancer types (52-58).

These reports are indicative for either protective or tumorigenic roles of the different GalNAc-Ts in cancer, suggesting a highly complex and rather specific O-glycosylation pattern of glycoproteins in the different cancer types. In this study we initially analyzed the expression levels of the selected five members of the polypeptide GalNAc-Ts family in EOC cell lines and EOC tumor samples (HGSCs) by western blotting. Similar, if not identical patterns of expression were observed 
for these GalNAc-Ts in both EOC cell lines and EOC tumors, as GALNT2 displayed very low or lack of expression in all EOC specimens studied, compared to control samples (including HOSE cells and non-tumoral ovarian tissues), while the expression levels of GALNT6, T9 and T14 were significantly higher in EOC cells and EOC tumors, as compared to very low/lack of expression in the corresponding controls (Fig. 1). Only GALNT4 showed very subtle, or absence of any expression in all EOC and control specimens analyzed, indicative for no implications of this enzyme in EOC progression (Fig. 1). These observations were further confirmed by performing IHC analysis of the protein expression levels in numerous EOC tumors and control tissues, using TMAs. Indeed, GALNT6, T9 and T14 exhibited very strong staining in HGSC tissues and very weak/no staining in the LMP tumors and control tissues, while GALNT2 displayed a rather inverse staining pattern indicative for a subtle or no expression in both HGSC and LMP tumors, compared to relatively strong expression in control tissues (Fig. 2). Again, lack of any staining was observed for GALNT4 in all (EOC tumor and control) tissue samples analyzed (Fig. 2). With the exception of GALNT4, our data are rather in accordance with previous studies for the roles of these GalNAc-Ts in different carcinoma types as summarized above, and suggest for a possible correlation of GALNT6, T9 and T14 expression with EOC progression, while a putative protective role of GALNT2 in EOC dissemination cannot be excluded.

Moreover, Kaplan-Meier survival curves and consecutive Cox-regression analyses revealed that the expression levels of two of the GalNAc-Ts analyzed (GALNT6 and GALNT14) were significantly related with poor PFS in the studied cohort of HG serous EOC patients (Fig. 4B and D and Table III), which suggests the putative use of these two transferases as novel prognostic serous EOC biomarkers. These results, as well as data from our previous study (15), are indicative for the significant inverse association of three members of the GalNAc-Ts gene family (GALNT3, T6 and T14) with disease progression in HGSC patients.

Furthermore, the simultaneous overexpression of four GalNAc-Ts (GALNT3, T6, T9 and T14) in advanced EOC raises the question about the specific and/or redundant functions of the members of this gene family in normal and pathological conditions, including EOC. Notably, it is known that the different GalNAc-Ts do have partially overlapping but distinct substrate specificities, which may result in these GalNAc-Ts having partial functional redundancy (59). So far, twenty members of the human GalNAc-Ts gene family have been identified (20), as such an abundance of GalNAc-Ts could provide substantial biosynthetic back-up. Although different GalNAc-Ts are differentially expressed within tissues, between cells, within a single tissue, and in different patterns at different stages in the development and differentiation, it is now becoming clear that a subset of the GalNAc-Ts display both distinct and overlapping substrate specificities $(11,13)$. Some of the mammalian GalNAc-transferase isoforms have been grouped into subfamilies based on their high homology $(11,20)$. One such example is the human subfamily comprised of GALNT3 and GALNT6, displaying 65\% homology in their coding sequence, although this homology does not provide complete functional redundancy (59). Interestingly, GALNT6 displayed quite similar oncogenic functions in breast cancer (modulating aberrant O-glycosylation and MUC1 stabilization) (39), as those found by us for GALNT3 in EOC (15). Increased GALNT3 and T6 co-expression has been detected in pancreatic (60) and renal (61) carcinomas, suggestive for GALNT3/T6 complementary correlations. As shown $(60,61)$, the upregulation of GALNT3 within the malignant transformation and progression of these cancers could partly depend on that of GALNT6 in both synergistic and compensatory ways. Moreover, not a separate GALNT3 or GALNT6 KD, but only double GALNT3/GALNT6 KD was shown to inhibit TGF $\beta$-induced epithelial-to-mesenchymal transition (EMT) in prostate cancer cells (35). Similarly, our western blotting and consecutive MCA analyses described herein (Fig. 3) are strongly suggestive for a possible functional overlap and redundancy of GALNT3 and T6 in EOC. Based on the above considerations we can suggest that different GalNAc-Ts perform redundant and/or overlapping functions in disease progression of women with HGSC. We believe that these relationships need to be examined further, both in vitro and in vivo to better understand how these transferases function together in initiating the biosynthesis of specific target glycoproteins, and if they actually demonstrate compensatory methods that may enhance their implication in disease progression.

In conclusion, we have shown that four members of the GalNAc-Ts gene family are differentially expressed in EOC specimens, as GALNT6, T9 and T14 were significantly overexpressed in both EOC cell lines and HGSCs, while GALNT2 displayed an inversed expression pattern indicative for very weak or no expression in both EOC cells and EOC tumors, compared to relatively strong expression in HOSE cells and control tissues. Importantly, GALNT6 and GALNT14 expression significantly correlated with poor prognosis of EOC patients with advanced disease. These data and our previously published data are indicative for a possible implication of different members of the GalNAc-Ts gene family (including GALNT2, T3, T6, T9 and T14) in modulating EOC progression, as GALNT6 and GALNT14, together with the previously characterized GALNT3, could represent novel prognostic EOC biomarkers. Moreover, our results are suggestive for overlapping functions of some GalNAc-Ts, and especially GALNT3 and GALNT6, in EOC, in conformity with GALNT3/T6 functional redundancy described in other cancer types. Further functional studies are warranted to more completely elucidate in vitro and in vivo the individual and/or synergistic implications of the members of the GalNAc-Ts gene family in ovarian tumorigenesis.

\section{Acknowledgements}

This study was supported by a grant to D.B. from the Cancer Research Society of Canada. Clinical specimens were provided by the 'Banque de tissus et de données of the Réseau de recherche sur le cancer' of the 'Fonds de recherche du Québec - Santé (FRQ-S)', associated with the Canadian Tumor Repository Network (CTRNet). We would also like to thank Ms. Anne-Sophie Julien from the 'Plateforme de Recherche Clinique du CHU de Québec-Université Laval' for helping us with the statistical analyses and interpretation 
of the data generated. In addition, we would like to thank Mr. Khaly Mbodji from the Department of Radi-oncologie and the 'Centre de recherché du Chu de Québec' for his help with the statistical analyses.

\section{References}

1. Siegel R, Ward E, Brawley O and Jemal A: Cancer statistics, 2011: The impact of eliminating socioeconomic and racial disparities on premature cancer deaths. CA Cancer J Clin 61: 212-236, 2011.

2. Fruscio R, Corso S, Ceppi L, Garavaglia D, Garbi A, Floriani I, Franchi D, Cantù MG, Bonazzi CM, Milani R, et al: Conservative management of early-stage epithelial ovarian cancer: Results of a large retrospective series. Ann Oncol 24: 138-144, 2013.

3. Alouini S: Management of ovarian cancer has changed. Gynecol Oncol 126: 313, author reply 314, 2012.

4. Pinho SS and Reis CA: Glycosylation in cancer: Mechanisms and clinical implications. Nat Rev Cancer 15: 540-555, 2015.

5. Stowell SR, Ju T and Cummings RD: Protein glycosylation in cancer. Annu Rev Pathol 10: 473-510, 2015.

6. Abbott KL: Glycomic analysis of ovarian cancer: Past, present, and future. Cancer Biomark 8: 273-280, 2010-2011.

7. Sheta R and Bachvarov D: Role of aberrant glycosylation in ovarian cancer dissemination. Biomedecial Rev 25: 83-92, 2014

8. Tabak LA: The role of mucin-type O-glycans in eukaryotic development. Semin Cell Dev Biol 21: 616-621, 2010.

9. Ten Hagen KG, Fritz TA and Tabak LA: All in the family: the UDP-GalNAc:polypeptide N-acetylgalactosaminyltransferases. Glycobiology 13: 1R-16R, 2003.

10. Hang HC and Bertozzi CR: The chemistry and biology of mucintype O-linked glycosylation. Bioorg Med Chem 13: 5021-5034, 2005.

11. Bennett EP, Mandel U, Clausen H, Gerken TA, Fritz TA and Tabak LA: Control of mucin-type O-glycosylation: A classification of the polypeptide GalNAc-transferase gene family. Glycobiology 22: 736-756, 2012.

12. Bennett EP, Hassan H, Mandel U, Mirgorodskaya E, Roepstorff P, Burchell J, Taylor-Papadimitriou J, Hollingsworth MA, Merkx G, van Kessel AG, et al: Cloning of a human UDP-N-acetyl-alpha-DGalactosamine:polypeptide $\mathrm{N}$-acetylgalactosaminyltransferase that complements other GalNAc-transferases in complete O-glycosylation of the MUC1 tandem repeat. J Biol Chem 273: 30472-30481, 1998.

13. Beaman EM and Brooks SA: The extended ppGalNAc-T family and their functional involvement in the metastatic cascade. Histol Histopathol 29: 293-304, 2014

14. Brooks SA, Carter TM, Bennett EP, Clausen H and Mandel U: Immunolocalisation of members of the polypeptide $\mathrm{N}$-acetylgalactosaminyl transferase (ppGalNAc-T) family is consistent with biologically relevant altered cell surface glycosylation in breast cancer. Acta Histochem 109: 273-284, 2007.

15. Wang ZQ, Bachvarova M, Morin C, Plante M, Gregoire J, Renaud MC, Sebastianelli A and Bachvarov D: Role of the polypeptide $\mathrm{N}$-acetylgalactosaminyltransferase 3 in ovarian cancer progression: Possible implications in abnormal mucin O-glycosylation. Oncotarget 5: 544-560, 2014.

16. Sheta R, Woo CM, Roux-Dalvai F, Fournier F, Bourassa $S$, Droit A, Bertozzi CR and Bachvarov D: A metabolic labeling approach for glycoproteomic analysis reveals altered glycoprotein expression upon GALNT3 knockdown in ovarian cancer cells. J Proteomics 145: 91-102, 2016.

17. Sheta R, Roux-Dalvai F, Woo CM, Fournier F, Bourassa S, Bertozzi CR, Droit A and Bachvarov D: Proteomic dataset for altered glycoprotein expression upon GALNT3 knockdown in ovarian cancer cells. Data Brief 8: 342-349, 2016.

18. Taylor PT and Haverstick D: Re: New guidelines to evaluate the response to treatment in solid tumors (ovarian cancer). J Natl Cancer Inst 97: 151, author reply 152, 2005

19. Elgaaen BV, Olstad OK, Sandvik L, Odegaard E, Sauer T, Staff AC and Gautvik KM: ZNF385B and VEGFA are strongly differentially expressed in serous ovarian carcinomas and correlate with survival. PLoS One 7: e46317, 2012.

20. Marth JD: Complexity in O-linked oligosaccharide biosynthesis engendered by multiple polypeptide $\mathrm{N}$-acetylgalactosaminyltransferases. Glycobiology 6: 701-705, 1996.

21. Dube DH and Bertozzi CR: Glycans in cancer and inflammation- potential for therapeutics and diagnostics. Nat Rev Drug Discov 4: 477-488, 2005
22. Hakomori S: Glycosylation defining cancer malignancy: New wine in an old bottle. Proc Natl Acad Sci USA 99: 10231-10233, 2002.

23. Christiansen MN, Chik J, Lee L, Anugraham M, Abrahams JL and Packer NH: Cell surface protein glycosylation in cancer. Proteomics 14: 525-546, 2014.

24. Fuster MM and Esko JD: The sweet and sour of cancer: Glycans as novel therapeutic targets. Nat Rev Cancer 5: 526-542, 2005.

25. Wang R, Yu C, Zhao D, Wu M and Yang Z: The mucin-type glycosylating enzyme polypeptide $\mathrm{N}$-acetylgalactosaminyltransferase 14 promotes the migration of ovarian cancer by modifying mucin 13. Oncol Rep 30: 667-676, 2013.

26. Lin MC, Huang MJ, Liu CH, Yang TL and Huang MC: GALNT2 enhances migration and invasion of oral squamous cell carcinoma by regulating EGFR glycosylation and activity. Oral Oncol 50: 478-484, 2014.

27. Ho WL, Chou CH, Jeng YM, Lu MY, Yang YL, Jou ST, Lin DT, Chang HH, Lin KH, Hsu WM, et al: GALNT2 suppresses malignant phenotypes through IGF-1 receptor and predicts favorable prognosis in neuroblastoma. Oncotarget 5: 12247-12259, 2014.

28. Wu YM, Liu CH, Hu RH, Huang MJ, Lee JJ, Chen CH, Huang J, Lai HS, Lee PH, Hsu WM, et al: Mucin glycosylating enzyme GALNT2 regulates the malignant character of hepatocellular carcinoma by modifying the EGF receptor. Cancer Res 71: 7270-7279, 2011

29. Liu SY, Shun CT, Hung KY, Juan HF, Hsu CL, Huang MC and Lai IR: Mucin glycosylating enzyme GALNT2 suppresses malignancy in gastric adenocarcinoma by reducing MET phosphorylation. Oncotarget 7: 11251-11262, 2016

30. Wright PK, May FE, Darby S, Saif R, Lennard TW and Westley BR: Estrogen regulates vesicle trafficking gene expression in EFF-3, EFM-19 and MCF-7 breast cancer cells. Int J Clin Exp Pathol 2: 463-475, 2009.

31. Niang B, Jin L, Chen X, Guo X, Zhang H, Wu Q, Padhiar AA, Xiao M, Fang D and Zhang J: GalNAc-T4 putatively modulates the estrogen regulatory network through FOXA1 glycosylation in human breast cancer cells. Mol Cell Biochem 411: 393-402, 2016.

32. Zhang J, Zhang Z, Wang Q, Xing XJ and Zhao Y: Overexpression of microRNA-365 inhibits breast cancer cell growth and chemoresistance through GALNT4. Eur Rev Med Pharmacol Sci 20: 4710-4718, 2016.

33. Liu Y, Liu W, Xu L, Liu H, Zhang W, Zhu Y, Xu J and Gu J: GALNT4 predicts clinical outcome in patients with clear cell renal cell carcinoma. J Urol 192: 1534-1541, 2014

34. Li Z, Yamada S, Wu Y, Wang KY, Liu YP, Uramoto H, Kohno K and Sasaguri Y: Polypeptide N-acetylgalactosaminyltransferase-6 expression independently predicts poor overall survival in patients with lung adenocarcinoma after curative resection. Oncotarget 7: 54463-54473, 2016

35. Freire-de-Lima L, Gelfenbeyn K, Ding Y, Mandel U, Clausen H, Handa $\mathrm{K}$ and Hakomori SI: Involvement of O-glycosylation defining oncofetal fibronectin in epithelial-mesenchymal transition process. Proc Natl Acad Sci USA 108: 17690-17695, 2011.

36. Tarhan YE, Kato T, Jang M, Haga Y, Ueda K, Nakamura Y and Park JH: Morphological changes, cadherin switching, and growth suppression in pancreatic cancer by GALNT6 knockdown. Neoplasia 18: 265-272, 2016.

37. Gomes J, Marcos NT, Berois N, Osinaga E, Magalhães A, Pinto-de-Sousa J, Almeida R, Gärtner F and Reis CA: Expression of UDP-N-acetyl-D-galactosamine: Polypeptide $\mathrm{N}$-acetylgalactosaminyltransferase-6 in gastric mucosa, intestinal metaplasia, and gastric carcinoma. J Histochem Cytochem 57: 79-86, 2009.

38. Liesche F, Kölbl AC, Ilmer M, Hutter S, Jeschke U and Andergassen U: Role of N-acetylgalactosaminyltransferase 6 in early tumorigenesis and formation of metastasis. Mol Med Rep 13: 4309-4314, 2016.

39. Park JH, Nishidate T, Kijima K, Ohashi T, Takegawa $K$, Fujikane T, Hirata K, Nakamura Y and Katagiri T: Critical roles of mucin 1 glycosylation by transactivated polypeptide $\mathrm{N}$-acetylgalactosaminyltransferase 6 in mammary carcinogenesis. Cancer Res 70: 2759-2769, 2010.

40. Park JH, Katagiri T, Chung S, Kijima K and Nakamura Y: Polypeptide N-acetylgalactosaminyltransferase 6 disrupts mammary acinar morphogenesis through O-glycosylation of fibronectin. Neoplasia 13: 320-326, 2011.

41. Berois N, Mazal D, Ubillos L, Trajtenberg F, Nicolas A, Sastre-Garau X, Magdelenat H and Osinaga E: UDP-N-acetyl-Dgalactosamine: Polypeptide N-acetylgalactosaminyltransferase- 6 as a new immunohistochemical breast cancer marker. J Histochem Cytochem 54: 317-328, 2006. 
42. Freire T, Berois N, Sóñora C, Varangot M, Barrios E and Osinaga E: UDP-N-acetyl-D-galactosamine:polypeptide $\mathrm{N}$-acetylgalactosaminyltransferase 6 (ppGalNAc-T6) mRNA as a potential new marker for detection of bone marrow-disseminated breast cancer cells. Int J Cancer 119: 1383-1388, 2006.

43. Patani N, Jiang W and Mokbel K: Prognostic utility of glycosyltransferase expression in breast cancer. Cancer Genomics Proteomics 5: 333-340, 2008.

44. Kölbl AC, Hiller RA, Ilmer M, Liesche F, Heublein S, Schröder L, Hutter S, Friese K, Jeschke U and Andergassen U: Glycosyltransferases as marker genes for the quantitative polymerase chain reaction-based detection of circulating tumour cells from blood samples of patients with breast cancer undergoing adjuvant therapy. Mol Med Rep 12: 2933-2938, 2015.

45. Pangeni RP, Channathodiyil P, Huen DS, Eagles LW, Johal BK, Pasha D, Hadjistephanou N, Nevell O, Davies CL, Adewumi AI, et al: The GALNT9, BNC1 and CCDC8 genes are frequently epigenetically dysregulated in breast tumours that metastasise to the brain. Clin Epigenetics 7: 57, 2015.

46. Berois N, Gattolliat CH, Barrios E, Capandeguy L, Douc-Rasy S, Valteau-Couanet D, Bénard J and Osinaga E: GALNT9 gene expression is a prognostic marker in neuroblastoma patients. Clin Chem 59: 225-233, 2013

47. Tuupanen S, Hänninen UA, Kondelin J, von Nandelstadh P, Cajuso T, Gylfe AE, Katainen R, Tanskanen T, Ristolainen H, Böhm J, et al: Identification of 33 candidate oncogenes by screening for base-specific mutations. Br J Cancer 111: $1657-1662,2014$

48. Keita M, Wang ZQ, Pelletier JF, Bachvarova M, Plante M, Gregoire J, Renaud MC, Mes-Masson AM, Paquet ÉR and Bachvarov D: Global methylation profiling in serous ovarian cancer is indicative for distinct aberrant DNA methylation signatures associated with tumor aggressiveness and disease progression. Gynecol Oncol 128: 356-363, 2013.

49. Huanna T, Tao Z, Xiangfei W, Longfei A, Yuanyuan X, Jianhua W, Cuifang Z, Manjing J, Wenjing C, Shaochuan Q, et al: GALNT14 mediates tumor invasion and migration in breast cancer cell MCF-7. Mol Carcinog 54: 1159-1171, 2015.

50. Wu C, Guo X, Wang W, Wang Y, Shan Y, Zhang B, Song W, Ma S, Ge J, Deng H, et al: N-Acetylgalactosaminyltransferase-14 as a potential biomarker for breast cancer by immunohistochemistry. BMC Cancer 10: 123, 2010.

51. Kwon OS, Oh E, Park JR, Lee JS, Bae GY, Koo JH, Kim H, Choi YL, Choi YS, Kim J, et al: GalNAc-T14 promotes metastasis through Wnt dependent HOXB9 expression in lung adenocarcinoma. Oncotarget 6: 41916-41928, 2015.
52. Wagner KW, Punnoose EA, Januario T, Lawrence DA, Pitti RM, Lancaster K, Lee D, von Goetz M, Yee SF, Totpal K, et al: Deathreceptor O-glycosylation controls tumor-cell sensitivity to the proapoptotic ligand Apo2L/TRAIL. Nat Med 13: 1070-1077, 2007.

53. Wu C, Shan Y, Liu X, Song W, Wang J, Zou M, Wang M and $\mathrm{Xu}$ D: GalNAc-T14 may be involved in regulating the apoptotic action of IGFBP-3. J Biosci 34: 389-395, 2009.

54. Liang KH, Lin CL, Chen SF, Chiu CW, Yang PC, Chang ML, Lin CC, Sung KF, Yeh C, Hung CF, et al: GALNT14 genotype effectively predicts the therapeutic response in unresectable hepatocellular carcinoma treated with transcatheter arterial chemoembolization. Pharmacogenomics 17: 353-366, 2016.

55. Lin WR, Chiang JM, Liang KH, Lim SN, Lai MW, Tsou YK, Hsieh TY, Hsu CK and Yeh CT: GALNT14 genotype predicts postoperative outcome of stage III colorectal cancer with oxaliplatin as adjuvant chemotherapy. Medicine (Baltimore) 95: e3487, 2016.

56. Liang KH, Lin CC and Yeh CT: GALNT14 SNP as a potential predictor of response to combination chemotherapy using 5-FU, mitoxantrone and cisplatin in advanced HCC.Pharmacogenomics 12: 1061-1073, 2011.

57. Soria JC, Márk Z, Zatloukal P, Szima B, Albert I, Juhász E, Pujol JL, Kozielski J, Baker N, Smethurst D, et al: Randomized phase II study of dulanermin in combination with paclitaxel, carboplatin, and bevacizumab in advanced non-small-cell lung cancer. J Clin Oncol 29: 4442-4451, 2011.

58. Thorburn A, Behbakht K and Ford H: TRAIL receptor-targeted therapeutics: Resistance mechanisms and strategies to avoid them. Drug Resist Updat 11: 17-24, 2008.

59. Bennett EP, Hassan H, Mandel U, Hollingsworth MA, Akisawa N, Ikematsu Y, Merkx G, van Kessel AG, Olofsson S and Clausen H: Cloning and characterization of a close homologue of human UDP-N-acetyl-alpha-D-galactosamine:Polypeptide $\mathrm{N}$-acetylgalactosaminyltransferase-T3, designated GalNAc-T6. Evidence for genetic but not functional redundancy. J Biol Chem 274: 25362-25370, 1999.

60. Li Z, Yamada S, Inenaga S, Imamura T, Wu Y, Wang KY, Shimajiri S, Nakano R, Izumi H, Kohno K, et al: Polypeptide $\mathrm{N}$-acetylgalactosaminyltransferase 6 expression in pancreatic cancer is an independent prognostic factor indicating better overall survival. Br J Cancer 104: 1882-1889, 2011.

61. Kitada S, Yamada S, Kuma A, Ouchi S, Tasaki T, Nabeshima A, Noguchi H, Wang KY, Shimajiri S, Nakano R, et al: Polypeptide $\mathrm{N}$-acetylgalactosaminyl transferase 3 independently predicts high-grade tumours and poor prognosis in patients with renal cell carcinomas. Br J Cancer 109: 472-481, 2013. 